\title{
LA NEUTRALIDAD DEL EMPRESARIO COMO LÍMITE A LA LIBERTAD RELIGIOSA DEL TRABAJADOR (COMENTARIO A LAS SENTENCIAS DE LA GRAN SALA DEL TRIBUNAL DE JUSTICIA DE LA UNIÓN EUROPEA DE 14 DE MARZO DE 2017)
}

\author{
Miguel RodríGuez Blanco \\ Catedrático de Derecho Eclesiástico del Estado. \\ Dpto. de Ciencias Jurídicas \\ Facultad de Derecho. \\ Universidad de Alcalá \\ miguel.rodriguez@uah.es
}

\section{SUPUESTO DE HECHO DE AMBOS CASOS Y PROBLEMÁTICA JURÍDICA PLANTEADA}

El 14 de marzo de 2017 la Gran Sala del Tribunal de Justicia de la Unión Europea (en adelante, TJUE) dictó dos sentencias sobre el uso de símbolos religiosos por los trabajadores en el desempeño de su actividad laboral. Ambos casos afectaban a trabajadoras de religión musulmana y al uso del pañuelo islámico durante la realización de la jornada laboral. Lo que se planteaba es si el empresario puede legítimamente prohibir el uso de símbolos religiosos por parte de sus trabajadores sin que eso suponga una discriminación por razón de religión de acuerdo con lo que establece la Directiva 2000/78/CE del Consejo, de 27 de noviembre de 2000, relativa al establecimiento de un marco general para la igualdad de trato en el empleo y la ocupación ${ }^{1}$. Los dos casos tienen su origen en sendas decisiones prejudiciales planteadas de acuerdo con el art. 267 del Tratado de Funcionamiento de la Unión Europea.

La primera de ellas, asunto C-157/15, fue planteada por el Tribunal de Casación de Bélgica. Las circunstancias del caso eran las siguientes: el

${ }^{1} \mathrm{Su}$ transposición a nuestro ordenamiento jurídico tuvo lugar por medio de la Ley 62/2003, de 30 de diciembre, de Medidas Fiscales, Administrativas y del Orden Social. 
12 de febrero de 2003 una mujer de confesión musulmana comenzó a trabajar como recepcionista para una empresa privada que presta servicios de recepción y acogida a clientes tanto del sector público como del sector privado. Regía en ese momento en el seno de la empresa una norma no escrita con arreglo a la cual los trabajadores no podían llevar signos visibles de sus convicciones políticas, filosóficas o religiosas en el lugar de trabajo. En abril de 2006 la trabajadora comunicó a sus superiores jerárquicos que a partir de entonces tenía la intención de llevar un pañuelo islámico durante las horas de trabajo. La dirección de la empresa le respondió que no se toleraría el uso de tal pañuelo porque ostentar signos políticos, filosóficos o religiosos era contrario a la neutralidad que la empresa se había impuesto seguir. El 29 de mayo de 2006 el comité de empresa aprobó una modificación del reglamento interno, que entró en vigor el 13 de junio de 2006, redactada en los siguientes términos: «Se prohíbe a los trabajadores llevar signos visibles de sus convicciones políticas, filosóficas o religiosas u observar cualquier rito derivado de éstas en el lugar de trabajo». La trabajadora no acató la norma y fue despedida.

Interpuesta demanda por despido, los distintos tribunales que conocieron del asunto desestimaron sus peticiones por considerar que la prohibición general de llevar signos visibles de convicciones políticas, filosóficas o religiosas en el lugar de trabajo no suponía una discriminación directa y tampoco se había observado ninguna discriminación indirecta o violación de la libertad individual o de la libertad de religión. En cuanto a la inexistencia de discriminación directa, se puso de manifiesto que la empleada no había sido despedida por profesar la fe musulmana, sino por persistir en su intención de hacerla patente durante las horas de trabajo llevando un pañuelo islámico. Según los órganos jurisdiccionales, la norma del reglamento interno conculcada por la demandante tiene un alcance general, puesto que prohíbe a cualquier trabajador llevar signos visibles de convicciones políticas, filosóficas o religiosas en el lugar de trabajo. La trabajadora interpuso un recurso de casación en el que adujo que al considerar que la prohibición dictada por la empresa constituye un criterio neutro y al no calificar esa prohibición de desigualdad de trato entre los trabajadores que llevan un pañuelo islámico y aquellos que no lo llevan por el hecho de que dicha prohibición no atañe a una convicción religiosa determinada y se aplica a todos los trabajadores, los tribunales no aplicaron correctamente los conceptos de «discriminación directa» y de «discriminación indirecta» en el sentido del art. 2, apartado 2, de la Directiva 2000/78. En estas circunstancias, el Tribunal de Casación 
decidió suspender el procedimiento y plantear al TJUE la siguiente cuestión prejudicial:

«¿Debe interpretarse el art. 2, apartado 2, letra a), de la Directiva 2000/78 en el sentido de que la prohibición de llevar un pañuelo como musulmana en el lugar de trabajo no constituye una discriminación directa si la norma en vigor en la empresa prohíbe a todos los trabajadores llevar en el lugar de trabajo signos externos de convicciones políticas, filosóficas o religiosas?».

La segunda decisión prejudicial, asunto C-188/15, trae causa de una petición cursada por el Tribunal de Casación de Francia que debía resolver el recurso de casación interpuesto por una trabajadora de religión musulmana. Esta empleada fue despedida mediante carta de fecha 22 de junio de 2009 en la que se le explicaba que un cliente de la empresa se había molestado porque llevaba un velo y había pedido a la empresa que «no hubiera velo la próxima vez». La empresa, durante el periodo de selección, le había manifestado a la trabajadora que respetaba su libertad de expresión y las convicciones religiosas personales, pero le advirtió que en las relaciones con los clientes imponían una política de discreción en lo que respecta a la expresión de las opciones personales de los empleados. Constatada la negativa de la trabajadora a prescindir del uso del velo, la empleadora considera que no puede realizar la prestación de trabajo y que debe proceder a la extinción de su contrato laboral.

La trabajadora consideró que el despido era discriminatorio y acudió a la jurisdicción laboral, donde su demanda fue desestimada por los tribunales inferiores que entendieron que la prohibición de llevar un pañuelo islámico estaba justificada por el hecho de que debía relacionarse con clientes de la empresa, la cual tenía derecho a preservar su imagen y no herir las convicciones de sus clientes. La empleada planteó entonces un recurso de casación en el que alegó que las restricciones a la libertad religiosa deben justificarse por la naturaleza de la tarea que deba realizarse y han de responder a un requisito profesional esencial y determinante, siempre, además, que el objetivo que persiguen sea legítimo y el requisito sea proporcionado. El Tribunal de Casación constató que el TJUE, en su Sentencia de 10 de julio de 2008, caso Feryn (C-54/07), sostuvo que el hecho de que un empleador declare públicamente que no contratará a trabajadores de determinado origen étnico o racial constituye una discriminación directa en la contratación en el sentido de la Directiva 2000/43/CE del Consejo, de 29 de junio de 2000, relativa a la 
aplicación del principio de igualdad de trato de las personas independientemente de su origen racial o étnico, pero no se pronunció sobre si debe interpretarse el art. 4, apartado 1, de la Directiva 2000/78 en el sentido de que el deseo del cliente de un empresario de que los servicios de éste no sigan siendo prestados por un trabajador por alguno de los motivos que son objeto de esta última Directiva constituye un requisito profesional esencial y determinante debido a la naturaleza de la actividad profesional concreta de que se trata o al contexto en que se lleva a cabo. En tales circunstancias, el Tribunal de Casación decidió suspender el procedimiento y plantear al TJUE la siguiente cuestión prejudicial:

«¿Debe interpretarse el art. 4, apartado 1, de la Directiva 2000/78 en el sentido de que el deseo manifestado por un cliente de una empresa de consultoría informática de que, en lo sucesivo, los servicios informáticos contratados no sean prestados por una asalariada de dicha empresa, ingeniero de proyectos, que usa un pañuelo islámico constituye un requisito profesional esencial y determinante, debido a la naturaleza de la actividad profesional concreta de que se trata o al contexto en que se lleva a cabo?».

Ambos casos tienen claras similitudes, pero presentan rasgos diferenciadores que han llevado al TJUE a realizar enfoques diferentes y a alcanzar conclusiones complementarias, en el sentido de que los fallos no son exactamente iguales. En el primer caso, el TJUE da respuestas a dos cuestiones: a) si una política de la empresa que prohíbe a todos los trabajadores llevar en el lugar de trabajo signos externos de convicciones políticas, filosóficas o religiosas supone una discriminación directa por razón de religión; $b$ ) si una política de ese tipo conlleva una discriminación indirecta por motivos religiosos. En el segundo pronunciamiento el TJUE se centra de forma directa en la siguiente cuestión: si la prohibición de portar un pañuelo islámico obedece a un requisito profesional esencial y determinante debido a la naturaleza de la actividad y al contexto profesional en que se desarrolla. Esta última cuestión, como veremos, afecta tanto a una posible discriminación directa como a una indirecta.

\section{LA DISCRIMINACIÓN DIRECTA POR RAZÓN DE RELIGIÓN}

Conforme al art. 2.2, letra a), de la Directiva 2000/78/CE, existirá discriminación directa por razón de religión cuando una persona sea, haya 
sido o pudiera ser tratada de manera menos favorable que otra en situación análoga por razón de su religión o convicciones. Como especifica el art. 3.1 de la norma, la prohibición de discriminación protege a todas las personas, por lo que respecta tanto al sector público como al privado, incluidos los organismos públicos, en relación con: a) las condiciones de acceso al empleo, a la actividad por cuenta propia y al ejercicio profesional, incluidos los criterios de selección y las condiciones de contratación y promoción, independientemente de la rama de actividad y en todos los niveles de la clasificación profesional, con inclusión de lo relativo a la promoción; b) el acceso a todos los tipos y niveles de orientación profesional, formación profesional, formación profesional superior y reciclaje, incluida la experiencia laboral práctica; c) las condiciones de empleo y trabajo, incluidas las de despido y remuneración; d) la afiliación y participación en una organización de trabajadores o de empresarios, o en cualquier organización cuyos miembros desempeñen una profesión concreta, incluidas las prestaciones concedidas por las mismas.

En el asunto C-157/15 la trabajadora de religión musulmana había sido despedida por negarse a cumplir la siguiente norma adoptada por la empresa: «Se prohíbe a los trabajadores llevar signos visibles de sus convicciones políticas, filosóficas o religiosas u observar cualquier rito derivado de éstas en el lugar de trabajo». Lo que se plantea es si la aprobación de una disposición de este tenor supone una discriminación directa por razón de religión.

El TJUE descarta que en este caso estemos ante una actuación que genere una discriminación directa con una argumentación que nos permitimos calificar de escueta. Sostiene que la norma interna controvertida en el litigio principal tiene por objeto el uso de signos visibles de convicciones políticas, filosóficas o religiosas y, por tanto, atañe indistintamente a cualquier manifestación de tales convicciones. Por consiguiente, debe considerarse que dicha norma trata por igual a todos los trabajadores de la empresa, ya que les impone, de forma general e indiferenciada, una neutralidad indumentaria que se opone al uso de tales signos. Lo cual se complementa con el dato que no consta en los autos que la aplicación de la norma a la demandante haya sido diferente de la aplicación de dicha disposición a cualquier otro trabajador. La conclusión que extrae de lo anterior es que la norma en cuestión no establece una diferencia de trato basada directamente en la religión o las convicciones en el sentido del art. 2, apartado 2, letra a), de la Directiva 2000/78. 
A nuestro modo de ver, la argumentación del Tribunal no es satisfactoria por tres motivos. En primer lugar, no nos parece que se pueda admitir, sin matizaciones, la afirmación de que estamos ante una norma neutral que se refiere no sólo a convicciones religiosas, sino también a la expresión de convicciones políticas o filosóficas. Choca esta afirmación con el dato recogido en los autos de que la norma fue aprobada por el comité de empresa una vez que la trabajadora de religión musulmana había comunicado al empleador su intención de llevar el pañuelo islámico y la dirección le había respondido que no se toleraría el uso de símbolos políticos, filosóficos o religiosos. No es descartable que la norma se disfrace de una vocación de generalidad cuando tiene en el fondo un carácter singular, dado que hasta que la demandante expresó que pensaba portar un símbolo religioso no se había adoptado ninguna reglamentación. Es útil traer a colación en este punto la Sentencia del Tribunal Supremo español de 14 de febrero de $2013^{2}$, relativa a un acuerdo del Ayuntamiento de Lérida en virtud del cual se modificaron varios artículos de una ordenanza municipal para limitar o prohibir el acceso o permanencia en determinados servicios municipales a las personas que porten «velo integral, pasamontañas, casco integral u otras vestimentas o accesorios» que impidan o dificulten la identificación y la comunicación visual de las personas. Ante la alegación del Ayuntamiento de que la medida tenía un carácter neutral, el Tribunal Supremo responde que es oportuno destacar que la prohibición del uso del velo integral en la ordenanza no es algo simplemente consecuencial, derivado de una prohibición inespecífica de atuendos que oculten el rostro, sino que no sólo tiene singularidad propia en la ordenanza, al referirse expresamente a ella, y como primero de los atuendos aludidos en la prohibición, sino que en la propia génesis de la modificación de la ordenanza ha sido precisamente el velo integral y el contraste cultural que el mismo plantea en el ámbito del Municipio de Lleida y su proclamada apreciación de lo que se considera que representa desde la posición de la mujer, elemento clave determinante de la reforma. Así lo constata el tribunal mediante la lectura en el expediente de los términos de la moción presentada al Pleno del Ayuntamiento de 28 de mayo de 2010 por determinados grupos municipales. Nos parece que en el caso analizado por el TJUE resulta discutible la neutralidad al omitir la causa inmediata que está presente en la adopción de la norma por parte de la empresa.

En segundo lugar, entendemos que no es correcto el concepto de neutralidad que subyace en el razonamiento del TJUE, pues su aplicación

\footnotetext{
2 RJ 2613.
} 
generalizada y sin las necesarias matizaciones podría dar lugar a situaciones de discriminación como las que quiere prohibir la Directiva 2000/78. En la postura del TJUE la neutralidad religiosa de la empresa equivale a la exigencia de prohibición de todo tipo de símbolos religiosos en los trabajadores. Esta postura no nos parece que sea propiamente de neutralidad hacia la religión, sino de exclusión del hecho religioso del ámbito propio de la empresa. Es como si una política de neutralidad en materia de discapacidad conllevara que la empresa adoptara la decisión de no contratar a personas con algún tipo de discapacidad reconocida para respetar los diversos tipos de discapacidad y no discriminar así entre las discapacidades físicas, las psíquicas o las sensoriales. La neutralidad conllevaría así la exclusión de trabajadores con diversidad funcional.

La noción de neutralidad que maneja, por ejemplo, el Tribunal Europeo de Derechos Humanos (en adelante, TEDH) es muy diferente. Así, en el apartado 116 del caso Iglesia Metropolitana de Besarabia y otros contra Moldavia, de 13 de diciembre de 2001, se afirma — postura reiterada en muchos otros pronunciamientos posteriores- que en el ejercicio de su poder de reglamentación en la materia y en su relación con las distintas religiones, cultos y creencias, el Estado debe permanecer neutral e imparcial. Con esa postura se mantiene el pluralismo y el buen funcionamiento de la democracia, una de cuyas principales características reside en la posibilidad que ofrece de resolver por medio del diálogo y sin recurrir a la violencia los problemas que encuentra un país, y ello incluso cuando éstos perturban. Por tanto, el papel de las autoridades en este caso «no es el de detener la causa de las tensiones eliminando el pluralismo, sino asegurar que los grupos enfrentados se toleren». Es decir, la neutralidad no se consigue mediante la eliminación de la religión, sino estableciendo unas condiciones de respeto mutuo y tolerancia recíprocas entre todas las manifestaciones de religiosidad.

Cuestión distinta sería si nos encontráramos ante tareas desempeñadas por empleados de la Administración o ante prestaciones que formen parte de los servicios públicos. En estos casos, siempre en función del concreto modelo de relaciones entre el Estado y las confesiones religiosas de cada país, puede ser legítimo un criterio de neutralidad que excluya las manifestaciones o expresiones religiosas, tal como razona el TEDH en el caso Ebrabimian contra Francia, de 26 de noviembre de 2015:

«El Tribunal ya ha admitido que los Estados pueden invocar los principios de laicidad y de neutralidad del Estado para justificar las restriccio- 
nes en cuanto a que los funcionarios lleven puestos símbolos religiosos, en especial los profesores de establecimientos públicos [...]. Es su condición de agentes públicos lo que les diferencia de los simples ciudadanos, los cuales "no están representando al Estado en el ejercicio de la función pública" y, por tanto, no "están sometidos, en base a un estatuto oficial a una obligación de discreción en la expresión pública de sus creencias religiosas” [...]. De igual forma, el Tribunal puede aceptar en las circunstancias del presente asunto que el Estado, que emplea a la demandante en un hospital público, en el que está en contacto con los pacientes, considera necesario que no manifieste sus creencias religiosas en el desempeño de sus funciones para garantizar la igualdad de trato de los enfermos. En este espíritu, la neutralidad del servicio público hospitalario puede considerarse relacionada con la actitud de sus agentes y como una exigencia de que los pacientes no puedan dudar de su imparcialidad» (apartado 64).

En tercer lugar, aun admitiendo que estuviéramos ante una disposición de carácter neutral y que entra dentro del ámbito competencial del poder de dirección del empresario, el TJUE debería haber reparado en el alcance del derecho fundamental de libertad religiosa, el cual constituye, al igual que los demás derechos fundamentales, un límite a la libertad de empresa. El Tribunal de Luxemburgo recurre expresamente al concepto de libertad religiosa adoptado por el TEDH, según el cual este derecho protege tanto el forum internum, esto es, el hecho de tener convicciones, como el forum externum, la manifestación pública de la fe religiosa. En efecto, el art. 9.1 del Convenio Europeo de Derechos Humanos protege una dimensión interna de la libertad religiosa, un claustro íntimo de creencias que faculta al individuo a adoptar libremente unas determinadas creencias con plena inmunidad de coacción, y una dimensión externa, que habilita a la persona a manifestar sus creencias, tanto de forma individual como colectiva, y tanto en público como en privado. Esta concepción del derecho de libertad religiosa, plenamente consolidada en la jurisprudencia constitucional española en consonancia con los tratados internacionales sobre derechos humanos ${ }^{3}$, se reitera en el caso Eweida y otros contra el Reino Unido, de 15 de enero de 2013:

«La libertad religiosa es principalmente una cuestión de conciencia y pensamiento individual. Este aspecto del derecho establecido en el párra-

3 Remitimos por todos a M. RodRíguEz Blanco, «Manifestaciones del derecho fundamental de libertad religiosa», en A. Álvarez Cortina y M. Rodríguez Blanco (coords.), La libertad religiosa en España. XXV años de vigencia de la Ley Orgánica 7/1980, de 5 de julio, de Libertad Religiosa, Comares, Granada, 2006, pp. 49 y ss. 
fo primero del art. 9, de tener cualquier creencia religiosa y a cambiar de religión o creencia, es absoluto e incondicional. Sin embargo, como se establece también en el art. 9.1, la libertad de religión comprende también la libertad de manifestar su creencia, solo y en privado, pero también para practicar en comunidad con otros y en público. La manifestación de una creencia religiosa puede adoptar la forma de culto, la enseñanza, la práctica y la observancia. El testimonio en palabras y hechos está vinculado con la existencia de convicciones religiosas» (apartado 80).

La dimensión externa de la libertad religiosa, precisa el propio Tribunal de Estrasburgo, dado que la manifestación por una persona de su creencia religiosa puede tener un impacto en otras, está sujeta a los límites que establece el art. 9.2 del Convenio, el cual dispone que cualquier limitación hacia una persona a manifestar su religión o creencia debe ser regulada por ley y ser necesaria en una sociedad democrática para la consecución de uno o más objetivos legítimos.

Tras estas precisiones, el TEDH puntualiza en el apartado 83 de la sentencia del caso Eweida que existe jurisprudencia del propio Tribunal y de la antigua Comisión Europea de Derechos Humanos que indica que si una persona es capaz de tomar medidas para evitar una limitación en su libertad de manifestar su religión o creencia, no hay injerencia con el derecho previsto en el art. 9.1 del Convenio y la limitación no requiere, por tanto, ser justificada en virtud del art. 9.2. Sin embargo, reconoce que no aplicó un enfoque similar respecto a las sanciones laborales impuestas a las personas como consecuencia del ejercicio de otros derechos protegidos por el Convenio (por ejemplo, el derecho al respeto a la vida privada en virtud del art. 8; el derecho a la libertad de expresión en virtud del art. 10; o el derecho negativo a no afiliarse a un sindicato del art. 11). Y concluye:

«Dada la importancia en una sociedad democrática de la libertad de religión, el Tribunal considera que, cuando una persona alega una restricción a la libertad de religión en el lugar de trabajo, en lugar de declarar que la posibilidad de cambiar de trabajo evitaría cualquier injerencia con el derecho, la mejor aproximación sería sopesar la posibilidad de considerar en el balance total si la restricción era proporcionada o no».

Respecto a la prohibición de discriminación por razón de religión que formula el art. 14 del Convenio Europeo de Derechos Humanos, el TEDH expresa en los apartados 87 y 88 de la Sentencia Eweida que para que se plantee una cuestión en virtud del art. 14 debe haber una diferencia de 
trato de las personas en situaciones análogas o similares. Sin embargo, esta no es la única faceta de la prohibición de la discriminación. El derecho a no ser discriminado en el goce de los derechos garantizados en el Convenio Europeo de Derechos Humanos también se vulnera cuando los Estados, sin una justificación objetiva y razonable, no tratan de forma diferente a las personas cuyas situaciones son significativamente diferentes. Esta diferencia de trato entre las personas en situaciones similares o no tratar de forma diferente a las personas en situaciones diferentes es discriminatoria si no tiene una justificación objetiva y razonable; en otras palabras, si no persigue un objetivo legítimo o si no hay una relación razonable de proporcionalidad entre los medios empleados y el objetivo perseguido.

De acuerdo con lo expuesto, consideramos que en este caso el TJUE debería haber partido de que la norma establecida por la empresa implica una injerencia en el ámbito de protección del derecho de libertad religiosa del que es titular la trabajadora. Para aplicarle esa prohibición general y no reconocerle el derecho a un tratamiento diferenciado se debería demostrar por parte del empresario - téngase en cuenta lo dispuesto en el art. 10.1 de la Directiva 2000/78/CE respecto a la carga de la prueba- ${ }^{4}$ que la medida responde a una justificación objetiva y razonable, en el sentido de guardar una relación de proporcionalidad entre el medio empleado y la finalidad perseguida. Nada de esto se exige en el pronunciamiento del Tribunal de Luxemburgo, que sólo entra en la ponderación al tratar la posible discriminación indirecta.

\section{LA DISCRIMINACIÓN INDIRECTA POR RAZÓN DE RELIGIÓN}

El art. 2.1, letra $b$ ), de la Directiva 2000/78/CE define la discriminación indirecta en los siguientes términos: existirá discriminación indirecta cuando una disposición, criterio o práctica aparentemente neutros pueda ocasionar una desventaja particular a personas con una religión o convic-

${ }^{4}$ Art. 10.1: «Los Estados miembros adoptarán con arreglo a su ordenamiento jurídico nacional, las medidas necesarias para garantizar que corresponda a la parte demandada demostrar que no ha habido vulneración del principio de igualdad de trato, cuando una persona que se considere perjudicada por la no aplicación, en lo que a ella se refiere, de dicho principio alegue, ante un tribunal u otro órgano competente, hechos que permitan presumir la existencia de discriminación directa o indirecta». 
ción, con una discapacidad, de una edad, o con una orientación sexual determinadas, respecto de otras personas, salvo que dicha disposición, criterio o práctica pueda justificarse objetivamente con una finalidad legítima y salvo que los medios para la consecución de esta finalidad sean adecuados y necesarios.

Al aplicar esta noción a los hechos del asunto C-157/15, el TJUE afir$\mathrm{ma}$, en primer lugar, que corresponde al juez nacional, que es el único competente para apreciar los hechos, determinar si, y en qué medida, la norma interna controvertida en el litigio principal es conforme con las exigencias mencionadas, esto es, si responde a una finalidad legítima y los medios empleados son adecuados y legítimos. No obstante, el TJUE debe proporcionar al juez nacional respuestas útiles, por lo que es competente para dar indicaciones, basadas en los autos del asunto principal y en las observaciones escritas y orales que se le han presentado, que permitan a ese juez resolver el litigio concreto del que conoce.

En cuanto al requisito de la existencia de una finalidad legítima, señala que ha de considerarse legítima la voluntad de seguir un régimen de neutralidad política, filosófica o religiosa en las relaciones con los clientes tanto del sector público como del sector privado. El deseo de un empresario de ofrecer una imagen neutra ante sus clientes está vinculado a la libertad de empresa y tiene, en principio, un carácter legítimo, en particular cuando el empresario sólo incluye en la persecución de esa finalidad a los trabajadores que van a estar en contacto con sus clientes. A nuestro modo de ver, esta conclusión sobre el alcance de la «finalidad legítima» restringe en exceso la noción de discriminación indirecta. Lo característico de este tipo de discriminación es que permite corregir situaciones discriminatorias no buscadas, ocasionadas de forma no intencionada por criterios, prácticas o disposiciones aparentemente neutrales y, por consiguiente, legítimos en vía de principio. Sería deseable que el TJUE hubiera traído a colación en este punto el alcance del derecho fundamental de libertad religiosa, que comprende la posibilidad de expresar las creencias profesadas a través de símbolos o de una determinada vestimenta, pues el poder de dirección, como hemos indicado, tiene como límite los derechos fundamentales del trabajador. De lo contrario, la discriminación indirecta podría devenir un concepto inoperativo en la práctica.

Por otra parte, cuando se habla de la finalidad legítima del criterio, práctica o disposición aparentemente neutro, se debe demostrar que la medida impuesta por el empresario responde a la tutela, promoción o protección de unos concretos bienes jurídicos, como podría ser garantizar la 
seguridad y salud de los propios trabajadores o de los clientes, o que el trabajador pueda llevar a cabo de forma correcta la actividad laboral, lo cual en determinados casos podría verse comprometido por el uso de prendas o símbolos religiosos.

Este aspecto entra en relación con el carácter adecuado de la norma objeto de controversia, respecto a lo cual el TJUE sostiene que el hecho de prohibir a los trabajadores el uso visible de signos de convicciones políticas, filosóficas o religiosas es apto para garantizar la correcta aplicación de un régimen de neutralidad, siempre que dicho régimen se persiga realmente de forma congruente y sistemática. En nuestra opinión, esta postura es discutible, pues como ya hemos apuntado depende de la noción de neutralidad religiosa que se maneje. El excluir todo símbolo religioso del ámbito de la empresa más que una postura de no tomar partido por ninguna creencia religiosa implica abogar abiertamente por eliminar las expresiones propias del derecho de libertad religiosa. Es más neutral permitir que cada trabajador exprese libremente sus creencias, seas éstas cuales sean, lo cual es una muestra de una verdadera neutralidad empresarial ante las manifestaciones de religiosidad que existen en la sociedad. Por lo demás, y al margen de la noción de neutralidad, es discutible que la postura empresarial en este punto deba afectar a la vestimenta y a los símbolos religiosos, pues que una persona exprese a través de su forma de vestir sus creencias religiosas no implica que en el desempeño de su actividad se vaya a comportar de forma contraria a la neutralidad en temas religiosos impuesta por la empresa. Lo que se le exige es que trate a todos los clientes por igual y que desempeñe sus funciones conforme a las exigencias de su puesto de trabajo sin verse condicionada o mediatizada por sus creencias.

Por lo que respecta al carácter necesario de la prohibición, el TJUE afirma que se debe comprobar si ésta se limita a lo estrictamente necesario. En concreto, ha de comprobarse si la prohibición del uso visible de cualquier signo o prenda de vestir que pueda asociarse a una creencia religiosa o a una convicción política o filosófica atañe únicamente a los trabajadores que están en contacto con los clientes. En tal caso, dicha prohibición deberá considerarse estrictamente necesaria para alcanzar la meta perseguida. No obstante, a continuación aboga por una especie de «acomodación razonable» o un juicio de ponderación, pues indica que corresponderá al tribunal remitente comprobar si, tomando en consideración las limitaciones propias de la empresa y sin que ello represente una carga adicional para ésta, la empresa tenía la posibilidad de ofrecer a la trabajadora un puesto de trabajo que no conllevara un contacto visual con los 
clientes en lugar de proceder a su despido. Incumbirá al tribunal remitente, a la luz de todos los elementos de los autos, sopesar los intereses presentes y limitar las restricciones de las libertades de que se trata a lo estrictamente necesario.

A nuestro modo de ver, es positiva esta referencia a la acomodación, pues supone admitir que la pretensión de la trabajadora de llevar un símbolo religioso es legítima y, por tanto, el empresario tiene el deber de respetar sus creencias en el ámbito de la empresa y buscarle un puesto alternativo. Aunque sea de forma tangencial, al final de la argumentación del TJUE sí se repara en que la libertad religiosa constituye un límite al poder de dirección empresarial y ha de ser tenida en cuenta en la toma de decisiones que afecten al empleado.

\section{EL ALCANCE DEL DERECHO A LA LIBERTAD RELIGIOSA Y LA EXISTENCIA DE UN REQUISITO PROFESIONAL ESENCIAL Y DETERMINANTE}

El art. 4.1 de la Directiva 2000/78/CE dispone que los Estados miembros podrán disponer que una diferencia de trato basada en la religión o las convicciones del trabajador no tendrá carácter discriminatorio, directo o indirecto, cuando debido a la naturaleza de la actividad profesional concreta de que se trate o al contexto en que se lleve a cabo, dicha característica constituya un requisito profesional esencial y determinante, siempre y cuando el objetivo sea legítimo y el objetivo proporcionado. Esta cuestión es abordada de forma directa por el TJUE en el caso C-188/15.

Lo primero que afirma el Tribunal es que ha tenido ocasión de declarar reiteradamente que se deduce del art. 4, apartado 1, de la Directiva 2000/78 que lo que debe constituir un requisito profesional esencial y determinante no es el motivo en el que se basa la diferencia de trato, sino una característica relacionada con dicho motivo. Y que sólo en muy contadas circunstancias una característica vinculada en particular a la religión puede constituir un requisito profesional esencial y determinante.

En segundo lugar, formula una puntualización muy relevante en este ámbito: a tenor del art. 4, apartado 1, de la Directiva 2000/78, la característica en cuestión únicamente puede constituir tal requisito «debido a la naturaleza de la actividad profesional concreta de que se trate o al contexto en que se lleve a cabo». Es decir, el empleador debe acreditar que el hecho de portar un símbolo religioso impide al trabajador llevar a cabo la 
actividad profesional y conlleva una ineptitud para el desempeño del puesto. Un ejemplo en este sentido podríamos encontrarlo en la Sentencia del Tribunal Superior de Justicia de Madrid de 27 de octubre de $1997^{5}$, relativa a una trabajadora musulmana que indicó a su empresario que sus creencias le impedían manipular productos derivados del cerdo o del alcohol. Si nos encontramos ante un supuesto en el que el trabajador necesariamente debe manejar ese tipo de productos en su actividad laboral, es indudable que estaríamos ante un requisito profesional esencial y determinante. En cambio, en temas como los analizados por el TJUE en las sentencias objeto de este comentario es altamente discutible que portar un pañuelo musulmán impida desempeñar un puesto de recepcionista o de ingeniero de proyectos. La prohibición del uso de símbolos religiosos no es aquí una exigencia profesional esencial y determinante.

El TJUE concluye su argumentación indicando que el concepto de «requisito profesional esencial y determinante», en el sentido del art. 4.1 de la Directiva 2000/78/CE, implica un requisito objetivamente dictado por la naturaleza de la actividad profesional de que se trate o por el contexto en que ésta se lleve a cabo. Por tanto, no ampara consideraciones subjetivas, como la voluntad del empresario de tener en cuenta los deseos particulares del cliente.

\section{CONCLUSIONES}

El TEDH cuenta con una doctrina jurisprudencial muy amplia sobre el contenido del derecho de libertad religiosa en sus diferentes manifestaciones: relaciones laborales, enseñanza, asistencia religiosa en establecimientos públicos, alimentación, lugares de culto, posición jurídica de las confesiones religiosas, etc. En cambio, el TJUE carece de una doctrina asentada sobre el alcance de este derecho fundamental. Los casos C-157/15 y C-188/15 han permitido al TJUE pronunciarse sobre el alcance de la prohibición de discriminación directa e indirecta por razón de religión recogida en la Directiva 2000/78/CE. Las conclusiones que ha alcanzado son las siguientes:

1. La prohibición de llevar un pañuelo islámico dimanante de una norma interna de una empresa privada que prohíbe el uso visible de cual-

\footnotetext{
5 AS $1997 \backslash 3751$.
} 
quier signo político, filosófico o religioso en el lugar de trabajo no constituye una discriminación directa por motivos de religión o convicciones en el sentido de esta Directiva. En cambio, tal norma interna de una empresa privada puede constituir una discriminación indirecta si se acredita que la obligación aparentemente neutra que contiene ocasiona, de hecho, una desventaja particular a aquellas personas que profesan una religión o tienen unas convicciones determinadas, salvo que pueda justificarse objetivamente con una finalidad legítima, como el seguimiento por parte del empresario de un régimen de neutralidad política, filosófica y religiosa en las relaciones con sus clientes, y que los medios para la consecución de esta finalidad sean adecuados y necesarios, extremos que corresponderá comprobar al órgano jurisdiccional remitente.

2. La voluntad de un empresario de tener en cuenta los deseos de un cliente de que los servicios de dicho empresario no sigan siendo prestados por una trabajadora que lleva un pañuelo islámico no puede considerarse un requisito profesional esencial y determinante en el sentido del art. 4.1 de la Directiva 2000/78/CE.

Ambas conclusiones permiten descartar prácticas discriminatorias, pero por las razones que hemos expuesto en las páginas precedentes, nos parece que el TJUE ha perdido una ocasión propicia para profundizar sobre el alcance del derecho a la libertad religiosa y fijar unas pautas sobre el juicio de ponderación que deben llevar a cabo los tribunales de los Estados miembros de la Unión cuando este derecho entra en conflicto con el poder de dirección del empresario o con los derechos de otros trabajadores. El TJUE ha mantenido una postura excesivamente reduccionista de la libertad religiosa y ha abogado por un concepto de neutralidad más próximo a la exclusión que a la imparcialidad, lo que le ha llevado a una postura más restrictiva del ejercicio de la libertad religiosa en el ámbito laboral que la sostenida por algunos tribunales españoles ${ }^{6}$.

${ }^{6}$ Cfr., a título de ejemplo, la Sentencia del Tribunal Superior de Justicia de Islas Baleares de 9 de septiembre de 2002 (AS 2003\2), sobre un conductor de autobús que solicita llevar la cabeza cubierta por ser de religión judía, y la Sentencia de 6 de febrero de 2017 del Juzgado de lo Social núm. 1 de Palma de Mallorca (AS 2017\8), relativa a una trabajadora que pretendía llevar un pañuelo islámico en su actividad laboral. 